\title{
Aplicação de extratos de folhas e tubérbulos de Cyperus rotundus L. e de auxinas sintéticas na estaquia caulinar de Duranta repens L.
}

\author{
REZENDE, F.P.F. ${ }^{1 *}$; ZUFFELLATO-RIBAS, K.C. ${ }^{1}$; KOEHLER, H.S. ${ }^{2}$ \\ ${ }^{1}$ Departamento de Botânica, ${ }^{2}$ Departamento de Fitotecnia e Fitossanitarismo, Universidade Federal do \\ Paraná, Avenida Coronel Francisco H dos Santos, s/n, Jardim das Américas, CEP: 81530-900, Curitiba - PR \\ *fernandafanti@gmail.com.
}

RESUMO: É de conhecimento popular que extratos de tiririca aumentam o enraizamento adventício de várias espécies, sendo esse procedimento utilizado na propagação vegetativa caseira. Uma vez que nesses extratos concentram grandes quantidades de auxinas e compostos fenólicos, o objetivo deste estudo pioneiro foi avaliar o efeito da aplicação de extratos de folhas e de tubérculos de Cyperus rotundus L. na estaquia caulinar de Duranta repens L., espécie considerada de fácil enraizamento, comparando sua ação à de auxinas sintéticas. As estacas foram coletadas em abril, junho, agosto, outubro e dezembro/2006 e fevereiro/2007 e confeccionadas com $8 \mathrm{~cm}$ de comprimento, com base cortada em bisel e corte reto acima da última gema, mantendo-se 4 folhas apicais. Os tratamentos foram: água e solução alcoólica $50 \%$ como controles; extrato de folhas e de tubérculos de C. rotundus $(25 \%, 50 \%$ e $100 \%)$; solução de ANA e AIB (500 e $1000 \mathrm{mg} \mathrm{L}^{-1}$ ), com imersão da base das estacas durante 10 segundos. As estacas foram mantidas sob nebulização, em tubetes contendo vermiculita, por 45 dias. Foram avaliadas a porcentagem de estacas enraizadas, número de raízes por estaca, comprimento das três maiores raízes por estaca $(\mathrm{cm})$ e a porcentagem de estacas vivas. Estacas coletadas nos meses de outubro e dezembro/2006 apresentaram as maiores porcentagens de enraizamento $(87,3 \%$ e $86,7 \%$, respectivamente) e maior número de raízes por estacas (9,5 e 10,4 raízes, respectivamente). O comprimento máximo das 3 maiores raízes $(10,2 \mathrm{~cm})$ foi obtido em estacas coletadas em dezembro/2006 e a maior taxa de sobrevivência $(60 \%)$ foi registrada na coleta de junho/2006 em estacas tratadas com 500 e $1000 \mathrm{mg} \mathrm{L}^{-1}$ de AlB. A aplicação dos extratos de folhas e de tubérculos de $C$. rotundus não apresentou diferença entre os resultados obtidos com a aplicação de ANA e AIB, os quais, por sua vez, também não influenciaram o enraizamento de estacas de D. repens em nenhuma das épocas avaliadas.

Palavras-chave: enraizamento, tiririca, pingo-de-ouro, AIB, ANA

ABSTRACT: Effect of Cyperus rotundus $L$. leaf and tuber extracts and synthetic auxins applied to stem cuttings of Duranta repens $\mathrm{L}$. It is known from popular tradition that extracts from nut grass increase the adventitious rooting of different species, being this procedure used in home-made vegetative propagation. Since in these extracts it is possible to find a large amount of auxins and phenolic compounds, the objective of this study was to evaluate the effect of the application of Cypreus rotundus L. leaves and tubers extracts in stem cuttings of Duranta repens L., a species considered of easy rooting, in comparison with the action of synthetic auxins. Cuttings were collected in april, june, august, october and december/2006 and february/2007 with $8 \mathrm{~cm}$ in length, diagonal cut at the bottom and a straight cut above the last bud, keeping four upper leaves. Treatments consisted of control (water and ethanol $50 \%$ ); extract from $C$. rotundus leaves and tubers (25, 50 and 100\%); NAA and IBA (500 and $1000 \mathrm{mg} \mathrm{L}^{-1}$ ), with immersion of the base of the cuttings for 10 seconds. Cuttings were kept in greenhouse under high moisture, in plastic containers containing vermiculite, for 45 days. The percentage of rooted cuttings, number of roots per cutting, length of the three longest roots per cutting $(\mathrm{cm})$ and the percentage of living cuttings were evaluated. Cuttings collected in october and december/2006 demonstrated the highest percentages of rooting (87.3\% and $86.7 \%$, respectively) and highest number of roots per cutting ( 9.5 and 10.4 roots, respectively). December/2006 cuttings showed the maximum length of the three largest roots $(10.2 \mathrm{~cm})$ and the best level of survival $(60 \%)$ was found in cuttings collected in june/2006 and treated with 500 and $1000 \mathrm{mg} \mathrm{L}^{-1}$ of IBA. Therefore,

Recebido para publicação em 18/03/2011

Aceito para publicação em 20/06/2013

Rev. Bras. PI. Med., Campinas, v.15, n.4, supl.I, p.639-645, 2013. 
we observed no statistical differences between the application of $C$. rotundus leaf and tuber extracts and the application of NAA and IBA.

Keywords: rooting, nut grass, golden dewdrop, IBA, NAA

\section{INTRODUÇÃO}

Cyperus rotundus L. (Cyperaceae), conhecida no Brasil como tiririca (Blanco, 2006), é considerada a planta daninha mais disseminada e agressiva de todo o mundo (Cudney, 1997; Durigan et al., 2005).

No Brasil C. rotundus é encontrada em toda a extensão territorial (Ricci et al., 2000; Durigan et al., 2005). Sua ampla distribuição capacidade de competição e agressividade, bem como à dificuldade de controle e erradicação (Durigan et al., 2005). Em muitos agroecossistemas é considerada como a principal planta daninha (Blanco, 2006), provocando reduções quantitativas e qualitativas na produção mundial das principais culturas (Cudney, 1997).

C. rotundus apresenta grande quantidade de compostos fenólicos e segundo Quayyum et al. (2000), os maiores níveis foram encontrados em extratos de folha, sendo que os componentes mais abundantes foram fenóis e ácidos graxos. Conci (2004) identificou a presença de terpenos e esteróides, flavonóides, alcalóides e taninos a partir de extrato alcoólico e aquoso de $C$. rotundus utilizando a cromatografia em camada delgada.

O óleo extraído de $C$. rotundus apresenta múltiplas atividades farmacológicas (Tam et al., 2007). No Brasil é mais comumente usado no tratamento de candidíase (Arantes et al., 2005), amenorréia e irregularidades menstruais, analgésico, sedativo, antiespasmódico e para aliviar a diarréia (Soumaya et al., 2005).

A estaquia é um método de propagação vegetativa de fácil execução, baixo custo e rapidez. Permite a obtenção de grande número de mudas com boa qualidade, sendo bastante empregada na propagação de espécies ornamentais e frutíferas (Hartmann et al., 2002). A indução de raízes em muitas espécies é dependente da aplicação de reguladores vegetais de natureza auxínica. Dentre elas, o ácido indol butírico (AIB) é o mais amplamente utilizado por ser estável à fotodegradação, seguido pelo ácido naftalenoacético (ANA). A aplicação exógena de auxinas atua na ativação de células do câmbio vascular, promovendo a formação de raízes adventícias em estacas (Hartmann et al., 2002).

Outro fator importante no enraizamento de estacas é a época de coleta destas a qual varia entre as espécies. O efeito da estação do ano na indução de raízes parece estar relacionado ao nível endógeno de auxina e mesmo com aplicação de reguladores vegetais nas estacas, essa relação é mantida (Zuffellato-Ribas \& Rodrigues, 2001). Assim, o efeito dos reguladores vegetais aplicados pode variar conforme a estação do ano, estimulando em uma ou até inibindo em outra (Iritani et al., 1986).

Uma vez que é difundido entre pequenos produtores rurais o uso de extratos de partes diversas da tiririca na promoção da propagação vegetativa, este estudo teve como objetivo estudar a aplicação de extratos de folhas e de tubérculos de C. rotundus em diferentes concentrações na indução de raízes em estacas caulinares de $D$. repens, sabidamente conhecida como uma espécie que responde bem ao enraizamento, comparando seus resultados com os efeitos da aplicação das auxinas sintéticas AIB e ANA, em algumas épocas de coleta.

O pingo-de-ouro (Duranta repens L.), Verbenaceae, é uma planta exótica originária do México e amplamente difundida no Brasil. Consiste num arbusto lenhoso que pode atingir até $1,5 \mathrm{~m}$ de altura. É muito utilizado em áreas de jardinagem e canteiros de vias urbanas, em bordaduras e renques a pleno sol e pode ser podado em variadas formas, moldando o espaço onde se encontra. Apresenta rápido crescimento e sua propagação para fins comerciais é feita por estaquia, principalmente no outono-inverno (Lorenzi \& Souza, 2001). No entanto, a propagação vegetativa via estaquia de $D$. repens pode ser realizada também em pleno verão (Bujokas et al., 2003).

\section{MATERIAL E MÉTODO}

Os experimentos foram conduzidos no Laboratório de Macropropagação do Setor de Ciências Biológicas da Universidade Federal do Paraná (UFPR). Extratos de C. rotundus (excicata UPCB 49737) foram obtidos de folhas e tubérculos frescos, segundo metodologia proposta por Simões et al. (2003). Os extratos obtidos foram peneirados e diluídos em água destilada em concentrações de $25 \%, 50 \%$ e $100 \%$. Após o preparo foram mantidos em geladeira por 24 horas antes da aplicação nas estacas.

Os ramos caulinares de $D$. repens (excicata MBM 306095) foram obtidos de plantas matrizes no Horto Municipal do Guabirotuba, em Curitiba - PR. As estacas foram confeccionadas com aproximadamente $8 \mathrm{~cm}$ de comprimento, sendo a

Rev. Bras. Pl. Med., Campinas, v.15, n.4, supl.I, p.639-645, 2013. 
base cortada em bisel e com corte reto no ápice mantendo-se 2 pares de folhas apicais. Após tratamento fitossanitário com hipoclorito de sódio a $0,5 \%$ por 15 minutos e lavagem em água corrente durante 5 minutos, suas bases foram imersas por 10 segundos nos seguintes tratamentos: testemunhas (água destilada e solução alcoólica 50\%); extrato de folhas e de tubérculos de $C$. rotundus $(25 \%, 50 \%$ e $100 \%$ ); solução de ANA e AIB (500 e $1000 \mathrm{mg} \mathrm{L}^{-1}$ ).

As estacas foram plantadas em tubetes de polipropileno $\left(53 \mathrm{~cm}^{3}\right)$ contendo vermiculita de granulometria média como substrato e mantidas em casa de vegetação com nebulização intermitente (24 $\pm 2^{\circ} \mathrm{C}$ e UR $=90 \%$ ).

Após 45 dias em leito de enraizamento foram avaliados os seguintes parâmetros: porcentagem de estacas enraizadas; número médio de raízes por estaca; comprimento médio das três maiores raízes por estaca $(\mathrm{cm})$ e porcentagem de estacas vivas (estacas que não formaram calos e não emitiram raízes). Os experimentos foram instalados em 6 épocas (abril, junho, agosto, outubro e dezembro de 2006 e fevereiro de 2007).

O delineamento experimental utilizado foi inteiramente casualizado, em esquema fatorial (12x6) constituído de 12 tratamentos, sendo eles: T1: Testemunha (água 100\%); T2: Testemunha (solução alcoólica 50\%); T3: Extrato de folhas de $C$. rotundus 25\%; T4: Extrato de folhas de $C$. rotundus $50 \%$, T4: Extrato de folhas de C. rotundus $100 \%$; T6: Extrato de tubérculos de C. rotundus 25\%; T7: Extrato de tubérculos de $C$. rotundus $50 \%$; T8: Extrato de tubérculos de C. rotundus 100\%; T9: ANA solução $500 \mathrm{mgL}^{-1}$; T10: ANA solução de $1000 \mathrm{mgL}^{-1}$; T11: AIB solução $500 \mathrm{mgL}^{-1}$ e T12: AIB solução 1000 $\mathrm{mgL}^{-1}$, e 4 repetições com 20 estacas por parcela.
Para testar a homogeneidade das médias os dados foram submetidos ao teste de Bartlett e análise de variância (teste F) e as médias foram comparadas pelo teste de Tukey a $5 \%$ de probabilidade. 0 programa estatístico utilizado foi o MSTATC.

\section{RESULTADO E DISCUSSÃO}

Analisando a porcentagem de estacas enraizadas, verificou-se que não houve interação entre os fatores tratamentos e épocas de coleta, indicando que estes são independentes (Tabela 1).

Estacas de $D$. repens coletadas durante a primavera e verão (outubro e dezembro de 2006 e fevereiro de 2007) apresentaram os melhores resultados na indução de raízes, $87,3 \%$, $86,7 \%$ e $80,7 \%$, respectivamente. Observou-se que estacas coletadas no período de inverno (junho/2006) apresentaram a menor porcentagem de enraizamento $(45,8 \%)$. Pode-se, portanto, constatar que a época de coleta das estacas foi determinante no enraizamento de estacas caulinares de $D$. repens e esses resultados corroboram os de Tofanelli et al. (2002). Esses autores relataram que a época de coleta das estacas de Prunus salicina foi um fator crítico no percentual de enraizamento desta espécie.

Ferreira et al. (2001) relataram ainda que ramos coletados no verão apresentam-se em pleno crescimento vegetativo, com grande emissão de gemas e folhas jovens, os quais são importantes fontes de auxinas endógenas. Ao contrário, estacas coletadas no inverno possuem maior grau de lignificação (Norberto et al., 2001; Dutra et al., 2002).

Analisando os diferentes tratamentos testados, verificou-se que não houve diferença estatística na porcentagem de estacas enraizadas.

TABELA 1. Comparação de médias das porcentagens de estacas enraizadas de Duranta repens.

\begin{tabular}{|c|c|c|c|c|c|c|c|}
\hline \multirow{2}{*}{ Tratamentos } & \multicolumn{6}{|l|}{ Épocas } & \multirow{2}{*}{$\begin{array}{l}\text { Média } \\
\text { geral }\end{array}$} \\
\hline & Abr/2006 & Jun/2006 & Ago/2006 & Out/2006 & Dez/2006 & Fev/2007 & \\
\hline Testemunha & 81,2 & 47,5 & 47,5 & 81,2 & 80,0 & 67,5 & 67,5 \\
\hline Test. alcoólica 50\% & 65,0 & 40,0 & 55,0 & 75,0 & 83,7 & 67,5 & 64,3 \\
\hline Extrato de folha $25 \%$ & 66,2 & 60,0 & 42,5 & 87,5 & 92,5 & 85,0 & 72,2 \\
\hline Extrato de folha $50 \%$ & 63,7 & 57,5 & 72,5 & 91,2 & 88,7 & 85,0 & 76,4 \\
\hline Extrato de folha $100 \%$ & 71,2 & 57,5 & 62,5 & 90,0 & 91,2 & 87,5 & 76,6 \\
\hline Extrato de tubérculo $25 \%$ & 86,2 & 45,0 & 58,7 & 90,0 & 81,2 & 80,0 & 73,5 \\
\hline Extrato de tubérculo $50 \%$ & 68,7 & 43,7 & 50,0 & 86,2 & 81,2 & 90,0 & 70,0 \\
\hline Extrato de tubérculo $100 \%$ & 77,5 & 45,0 & 43,7 & 96,2 & 87,5 & 83,7 & 72,2 \\
\hline $500 \mathrm{mg} \mathrm{L}^{-1}$ de ANA & 75,0 & 50,0 & 43,7 & 95,0 & 96,2 & 75,0 & 72,5 \\
\hline $1000 \mathrm{mg} \mathrm{L}^{-1}$ de ANA & 90,0 & 40,0 & 41,2 & 90,0 & 91,2 & 85,0 & 72,9 \\
\hline $500 \mathrm{mg} \mathrm{L}^{-1}$ de AlB & 76,2 & 27,5 & 47,5 & 88,7 & 83,7 & 77,5 & 66,9 \\
\hline $1000 \mathrm{mg} \mathrm{L}^{-1}$ de AIB & 83,7 & 36,2 & 47,5 & 77,5 & 83,7 & 85,0 & 68,9 \\
\hline Média geral & $75,4 \mathrm{~B}$ & $45,8 \mathrm{C}$ & $51,0 \mathrm{C}$ & $87,3 \mathrm{~A}$ & $86,7 \mathrm{~A}$ & $80,7 \mathrm{AB}$ & \\
\hline Coeficiente de variação (\%) & 20,36 & & & & & & \\
\hline
\end{tabular}

Médias seguidas da mesma letra maiúscula na linha não diferem estatisticamente pelo teste de Tukey ao nível de $5 \%$ de probabilidade. 
No entanto, foi possível observar que extratos obtidos de folhas de C. rotundus a $50 \%$ e $100 \%$ apresentaram as maiores médias numéricas com $76,4 \%$ e $76,6 \%$ de estacas enraizadas, respectivamente (Tabela 1). Meguro (1969) confirmou a presença de ácido indol acético (AIA) em tubérculos de C. rotundus e Souza et al. (2003) relataram a presença de substâncias alelopáticas nas folhas de $C$. rotundus. Tais compostos foram importantes na indução de primórdios radiciais em estacas caulinares de $D$. repens.

Com relação ao número de raízes por estaca, foi possível observar que não houve interação entre os fatores, mostrando que estes são independentes (Tabela 2).

O número médio de raízes por estaca foi influenciado pela época de coleta, sendo que as melhores respostas foram obtidas nas estacas coletadas em outubro e dezembro/2006, apresentando 9,5 e 10,4 raízes por estaca, respectivamente (Tabela 2). Segundo Norberto et al. (2001), as estacas coletadas em período de crescimento vegetativo intenso (primavera/verão) possuem maior capacidade de enraizamento. Desta forma, os resultados obtidos no presente trabalho corroboram os de Dutra et al. (2002) que também obtiveram o maior número de raízes por estaca de Prunus persica L. no período da primavera/verão. Este fator é atribuído ao fato da planta matriz estar em um período de crescimento vegetativo intenso, onde seus ramos apresentam-se mais herbáceos e de modo geral, mostram maior capacidade de enraizamento.

As estacas de $D$. repens coletadas em abril de 2006 formaram o menor número de raízes por estaca (6,9 raízes); no entanto, este valor pode ser considerado elevado. Bitencourt (2004), trabalhando com estacas de $D$. repens sem folhas, não obteve estacas enraizadas, enquanto que, em estacas contendo 4 folhas apicais o número máximo de raízes obtidas foi 5,5 raízes por estaca. Neste estudo, a formação de 10,4 raízes por estaca pode ser atribuído ao fato das estacas apresentarem folhas, as quais servem como fonte de produção de auxina e carboidratos favorecendo a emissão de raízes, uma vez que a formação de um sistema radicial bem desenvolvido com numerosas raízes favorece a absorção e sobrevivência das mudas no campo.

Com relação ao comprimento médio das 3 maiores raízes por estaca, foi possível observar que os resultados foram independentes, podendo ser analisado isoladamente a melhor época e o melhor tratamento (Tabela 3).

O maior comprimento médio das 3 maiores raízes formadas $(10,2 \mathrm{~cm})$ foi observado em estacas coletadas em dezembro de 2006, diferindo das demais épocas (Tabela 3). Nesta época, o aumento no comprimento das raízes pode ser atribuído ao maior acúmulo de nutrientes na planta matriz. Comparando os tratamentos, é possível observar que a maior média numérica $(7,0 \mathrm{~cm})$ foi obtida com a aplicação de $500 \mathrm{mg} \mathrm{L}^{-1}$ de AIB.

Os resultados obtidos no presente trabalho não corroboram os de Bitencourt (2004). Este autor relata que o maior comprimento médio das raízes em estacas de $D$. repens foi obtido com a aplicação de $1000 \mathrm{mg} \mathrm{L}^{-1}$ de ANA $(4,5 \mathrm{~cm})$ ao passo que, a

TABELA 2. Comparação de médias do número de raízes por estaca de Duranta repens.

\begin{tabular}{|c|c|c|c|c|c|c|c|}
\hline \multirow{2}{*}{ Tratamentos } & \multicolumn{6}{|c|}{ Épocas } & \multirow{2}{*}{$\begin{array}{r}\text { Média } \\
\text { geral }\end{array}$} \\
\hline & Abr/2006 & Jun/2006 & Ago/2006 & Out/2006 & Dez/2006 & Fev/2007 & \\
\hline Testemunha & 8,1 & 10,1 & 7,0 & 8,6 & 9,8 & 8,7 & 8,7 \\
\hline Test. alcoólica $50 \%$ & 5,8 & 5,1 & 6,8 & 7,4 & 11,1 & 8,7 & 7,5 \\
\hline Extrato de folha $25 \%$ & 6,4 & 9,1 & 7,9 & 8,0 & 12,8 & 9,7 & 9,0 \\
\hline Extrato de folha $50 \%$ & 6,5 & 9,1 & 7,9 & 9,1 & 10,5 & 8,9 & 8,7 \\
\hline Extrato de folha $100 \%$ & 4,5 & 11,0 & 8,3 & 10,3 & 10,0 & 8,8 & 8,8 \\
\hline Extrato de tubérculo $25 \%$ & 5,8 & 8,7 & 7,2 & 9,5 & 9,8 & 8,8 & 8,3 \\
\hline Extrato de tubérculo $50 \%$ & 5,4 & 9,2 & 6,2 & 9,9 & 8,9 & 9,3 & 8,1 \\
\hline Extrato de tubérculo $100 \%$ & 7,4 & 8,6 & 6,1 & 10,8 & 10,9 & 7,9 & 8,6 \\
\hline $500 \mathrm{mg} \mathrm{L}^{-1} \mathrm{de}$ ANA & 8,3 & 8,0 & 5,2 & 10,5 & 9,6 & 9,8 & 8,6 \\
\hline $1000 \mathrm{mg} \mathrm{L}^{-1}$ de ANA & 9,2 & 5,6 & 5,6 & 9,8 & 11,1 & 9,4 & 8,4 \\
\hline $500 \mathrm{mg} \mathrm{L}^{-1}$ de AIB & 7,0 & 6,5 & 9,7 & 11,9 & 10,5 & 7,5 & 8,9 \\
\hline $1000 \mathrm{mg} \mathrm{L}^{-1} \mathrm{de}$ AlB & 8,4 & 7,8 & 6,3 & 8,2 & 9,6 & 8,6 & 8,1 \\
\hline Média geral & $6,9 \mathrm{D}$ & $8,2 \mathrm{BC}$ & $7,0 \mathrm{CD}$ & $9,5 \mathrm{AB}$ & $10,4 \mathrm{~A}$ & $8,8 \mathrm{~B}$ & \\
\hline Coeficiente de variação (\%) & \multicolumn{6}{|c|}{25,86} & \\
\hline
\end{tabular}

Médias seguidas da mesma letra maiúscula na linha não diferem estatisticamente pelo teste de Tukey ao nível de $5 \%$ de probabilidade.

Rev. Bras. PI. Med., Campinas, v.15, n.4, supl.I, p.639-645, 2013. 
TABELA 3. Comparação do comprimento médio $(\mathrm{cm})$ das 3 maiores raízes por estaca de Duranta repens.

\begin{tabular}{|c|c|c|c|c|c|c|c|}
\hline \multirow{2}{*}{ Tratamentos } & \multicolumn{6}{|c|}{ Épocas } & \multirow{2}{*}{$\begin{array}{l}\text { Média } \\
\text { geral }\end{array}$} \\
\hline & Abr/2006 & Abr/2006 & Abr/2006 & Out/2006 & Out/2006 & Out/2006 & \\
\hline Testemunha & 4,0 & 3,3 & 3,4 & 7,4 & 10,0 & 8,4 & $6,1 \mathrm{ab}$ \\
\hline Test. alcoólica 50\% & 3,0 & 2,6 & 3,3 & 7,4 & 9,0 & 7,1 & $5,4 \mathrm{~b}$ \\
\hline Extrato de folha $25 \%$ & 2,1 & 3,7 & 4,1 & 8,0 & 10,0 & 9,1 & $6,2 a b$ \\
\hline Extrato de folha $50 \%$ & 4,0 & 3,9 & 3,6 & 7,3 & 9,9 & 9,0 & $6,3 a b$ \\
\hline Extrato de folha $100 \%$ & 1,7 & $3,4 w$ & 3,9 & 8,4 & 9,9 & 9,1 & $6,1 \mathrm{ab}$ \\
\hline Extrato de tubérculo $25 \%$ & 1,6 & 4,8 & 4,1 & 7,7 & 10,4 & 8,4 & $6,2 a b$ \\
\hline Extrato de tubérculo $50 \%$ & 2,2 & 3,5 & 3,3 & 8,6 & 10,5 & 9,2 & $6,2 a b$ \\
\hline Extrato de tubérculo $100 \%$ & 2,9 & 3,5 & 4,5 & 7,9 & 10,5 & 9,4 & $6,4 a b$ \\
\hline $500 \mathrm{mg} \mathrm{L}^{-1}$ de ANA & 4,0 & 4,0 & 3,4 & 7,6 & 10,8 & 9,3 & $6,5 a b$ \\
\hline $1000 \mathrm{mg} \mathrm{L}^{-1} \mathrm{de}$ ANA & 4,9 & 3,3 & 4,0 & 8,4 & 11,0 & 8,8 & 6,7 a \\
\hline $500 \mathrm{mg} \mathrm{L}^{-1} \mathrm{de}$ AIB & 4,4 & 3,9 & 5,3 & 9,7 & 10,3 & 8,6 & $7,0 \mathrm{a}$ \\
\hline $1000 \mathrm{mg} \mathrm{L}^{-1}$ de AIB & 5,3 & 2,9 & 4,4 & 8,6 & 10,6 & 8,8 & $6,7 \mathrm{a}$ \\
\hline Média geral & $3,3 \mathrm{C}$ & $3,6 \mathrm{C}$ & $3,9 \mathrm{C}$ & $8,1 \mathrm{~B}$ & $10,2 \mathrm{~A}$ & $8,7 \mathrm{~B}$ & \\
\hline Coeficiente de variação (\%) & \multicolumn{6}{|c|}{18,19} & \\
\hline
\end{tabular}

Médias seguidas da mesma letra maiúscula na linha e minúscula na coluna não diferem estatisticamente pelo teste de Tukey ao nível de $5 \%$ de probabilidade.

utilização de $500 \mathrm{mg} \mathrm{L}^{-1}$ de ANA o comprimento máximo das raízes foi de $1,9 \mathrm{~cm}$, mantendo as estacas após 30 dias. No entanto, no presente trabalho as estacas permaneceram em leito de enraizamento por 45 dias e esse período maior possivelmente favoreceu o crescimento das raízes.

Bujokas et al. (2003) relataram que o maior comprimento médio de raízes por estacas de $D$. repens $(6,8 \mathrm{~cm})$ foi obtido com a aplicação de 5000 $\mathrm{mg} \mathrm{L}^{-1}$ de ANA. No entanto, o comprimento máximo das raízes obtidos no presente trabalho $(7 \mathrm{~cm})$ foi obtido com a aplicação de $500 \mathrm{mg} \mathrm{L}^{-1}$ de ANA.

Para a variável estacas vivas, a interação entre os fatores tratamentos e épocas foi significativa, indicando que os fatores não são independentes (Tabela 4).

O maior índice de estacas vivas, que não emitiram raízes $(60 \%)$ foi obtido em estacas coletadas em junho de 2006 e tratadas com 500 e $1000 \mathrm{mg} \mathrm{L}^{-1}$ de AIB (Tabela 4). Dutra et al. (2002) relataram que quando as estacas estão mais lignificadas possuem menor capacidade de

TABELA 4. Comparação de médias das porcentagens de estacas de Duranta repens vivas.

\begin{tabular}{|c|c|c|c|c|c|c|c|}
\hline \multirow[t]{2}{*}{ Tratamentos } & \multicolumn{6}{|c|}{ Épocas } & \multirow{2}{*}{$\begin{array}{c}\text { Média } \\
\text { geral }\end{array}$} \\
\hline & Abr/2006 & Jun/2006 & Ago/2006 & Out/2006 & Dez/2006 & Fev/2007 & \\
\hline Testemunha & $2,5 \mathrm{C} \mathrm{a}$ & $45,0 \mathrm{~A}$ a & $52,5 \mathrm{~A} a b$ & $18,7 \mathrm{BC}$ a & $20,0 \mathrm{BC}$ a & $32,5 \mathrm{AB}$ a & $28,5 a b$ \\
\hline Test. Alcoólica 50\% & $5,0 \mathrm{D} \mathrm{a}$ & $60,0 \mathrm{Aa}$ & $45,0 \mathrm{AB} a b$ & $25,0 \mathrm{BCD}$ a & $13,7 \mathrm{CD}$ a & $32,5 \mathrm{BC}$ a & 30,2 a \\
\hline Extrato de folha $25 \%$ & $5,0 \mathrm{C} \mathrm{a}$ & $36,2 \mathrm{AB}$ a & $57,5 \mathrm{~A}$ a & $12,5 \mathrm{C} \mathrm{a}$ & $5,0 \mathrm{C} \mathrm{a}$ & $15,0 \mathrm{BC}$ a & $21,8 \mathrm{abc}$ \\
\hline Extrato de folha $50 \%$ & $8,7 \mathrm{~B} \mathrm{a}$ & $42,5 \mathrm{~A} a$ & $27,5 \mathrm{AB} b$ & $8,7 \mathrm{~B} \mathrm{a}$ & $9,5 \mathrm{~B} \mathrm{a}$ & $15,0 \mathrm{~B}$ a & 18,6 bc \\
\hline Extrato de folha $100 \%$ & $3,7 \mathrm{~B} \mathrm{a}$ & $40,0 \mathrm{~A}$ a & $37,5 \mathrm{~A} a b$ & $10,0 \mathrm{~B}$ a & $5,0 \mathrm{~B} \mathrm{a}$ & $12,5 \mathrm{~B}$ a & $18,1 \mathrm{c}$ \\
\hline Extrato de tubérculo $25 \%$ & $0,0 \mathrm{C} \mathrm{a}$ & $53,7 \mathrm{~A}$ a & $41,2 \mathrm{AB} a b$ & $10,0 \mathrm{C} \mathrm{a}$ & $21,2 \mathrm{BC}$ a & $20,0 \mathrm{BC}$ a & $24,3 \mathrm{abc}$ \\
\hline Extrato de tubérculo $50 \%$ & $0,0 \mathrm{~B} \mathrm{a}$ & $46,2 \mathrm{~A} a$ & $50,0 \mathrm{~A} \mathrm{ab}$ & $11,2 \mathrm{~B}$ a & $16,2 \mathrm{~B}$ a & $10,0 \mathrm{~B}$ a & $22,2 \mathrm{abc}$ \\
\hline Extrato de tubérculo $100 \%$ & $1,2 \mathrm{~B} \mathrm{a}$ & $51,2 \mathrm{~A} a$ & $56,2 \mathrm{~A} a$ & $1,2 \mathrm{~B}$ a & $12,5 \mathrm{~B}$ a & $16,2 \mathrm{~B}$ a & $23,1 \mathrm{abc}$ \\
\hline $500 \mathrm{mg} \mathrm{L}^{-1} \mathrm{de}$ ANA & $6,2 \mathrm{CD}$ a & $40,0 \mathrm{AB}$ a & $56,2 \mathrm{~A} a$ & $5,0 \mathrm{CD}$ a & $2,5 \mathrm{D}$ a & $25,0 \mathrm{BC}$ a & $22,5 \mathrm{abc}$ \\
\hline $1000 \mathrm{mg} \mathrm{L}^{-1}$ de ANA & $6,2 \mathrm{~B}$ a & $55,0 \mathrm{~A} a$ & $58,7 \mathrm{~A} a$ & $8,7 \mathrm{~B}$ a & $8,7 \mathrm{~B} \mathrm{a}$ & $15,0 \mathrm{~B}$ a & $25,4 \mathrm{abc}$ \\
\hline $500 \mathrm{mg} \mathrm{L}^{-1} \mathrm{de}$ AIB & $3,7 \mathrm{~B} \mathrm{a}$ & $60,0 \mathrm{~A} \mathrm{a}$ & $52,5 \mathrm{~A} a b$ & $10,0 \mathrm{~B}$ a & $15,0 \mathrm{~B}$ a & $22,5 \mathrm{~B}$ a & $27,2 \mathrm{abc}$ \\
\hline $1000 \mathrm{mg} \mathrm{L}^{-1}$ de AIB & $1,2 \mathrm{~B}$ a & $60,0 \mathrm{~A} \mathrm{a}$ & $52,5 \mathrm{~A} a b$ & $22,5 \mathrm{~B}$ a & $11,2 \mathrm{Ba}$ & $15,0 \mathrm{~B}$ a & $27,0 \mathrm{abc}$ \\
\hline Média geral & $3,6 \mathrm{~B}$ & $49,1 \mathrm{~A}$ & $48,9 \mathrm{~A}$ & $11,9 \mathrm{~A}$ & $11,7 \mathrm{C}$ & $19,2 \mathrm{~B}$ & \\
\hline Coeficiente de variação (\%) & & & & 3,69 & & & \\
\hline
\end{tabular}

Médias seguidas da mesma letra maiúscula na linha e minúscula na coluna não diferem estatisticamente pelo teste de Tukey ao nível de $5 \%$ de probabilidade.

Rev. Bras. PI. Med., Campinas, v.15, n.4, supl.I, p.639-645, 2013. 
enraizamento. Este fato pode ser observado uma vez que no inverno as planta matrizes encontram-se em período de dormência.

Os resultados do presente trabalho não corroboram os de Bujokas et al. (2003) que relataram baixa porcentagem de estacas de $D$. repens vivas (6,6\%), ao passo que Bitencourt (2004) obteve uma porcentagem maior com $30 \%$ de estacas vivas de D. repens com a aplicação de $500 \mathrm{mg} \mathrm{L}^{-1}$ de AIB, e com $1000 \mathrm{mg} \mathrm{L}^{-1}$ de ANA, apenas $1,3 \%$ de estacas não emitiram raízes.

Rocha et al. (2004), relataram que estacas de Nerium oleander submetidas ao tratamento com $2000 \mathrm{mg} \mathrm{L}^{-1}$ de AIB não apresentaram estacas vivas. O mesmo foi relatado por Bordim et al. (2003) onde a aplicação de $2000 \mathrm{mg} \mathrm{L}^{-1}$ de AIB proporcionou apenas $4 \%$ de estacas vivas, enquanto que, na ausência de regulador vegetal $16 \%$ das estacas de Malpighia emarginata permaneceram vivas. Desta forma, os resultados obtidos no presente trabalho não corroboram os de Rocha et al. (2204) e Bordim et al. (2003), onde a maior porcentagem de estacas vivas foi obtido com a utilização de AIB.

\section{CONCLUSÃO}

A aplicação de extratos de folhas e de tubérculos de $C$. rotundus não influenciou o enraizamento de estacas de $D$. repens em nenhuma das épocas avaliadas. Os tratamentos com auxinas não aumentaram o enraizamento desta espécie em relação aos controles que apresentaram índice elevado de formação radicial $(67,5 \%$ e $64,3 \%)$. As coletas realizadas na primavera (outubro) e verão (dezembro) foram as que apresentaram maiores resultados para o enraizamento de estacas de $D$. repens independente do tratamento aplicado (87,3\% e $86,7 \%$, respectivamente). As mesmas épocas também se mostraram melhores para as variáveis número de raízes por estaca $(9,5$ e 10,4) e comprimento médio das 3 maiores raízes por estaca $(8,1$ e 10,2).

\section{REFERÊNCIA}

ARANTES, M.C.B. et al. Estudo farmacognóstico do Cyperus rotundus L. Revista Eletrônica de Farmácia, v.2, n.2, p.17-20, 2005.

BITENCOURT, J. Propagação vegetativa de Duranta repens L.. 2004. 31p. Monografia (Graduação em Ciências Biológicas) - Universidade Federal do Paraná, Curitiba.

BLANCO, F.M.G. Tubérculo Invasor. Caderno Técnico Cultivar, n.90, p.2-7, 2006.

BORDIM, I. et al. Enraizamento de estacas de acerola sob concentrações de ácido indol-butírico. Semina, v.24, n.2, p.261-4, 2003.
BUJOKAS, W.M. et al. Propagação vegetativa de Duranta repens L. via estaquia pela aplicação de auxinas sintéticas. Cultura Agronômica, v.12, n.1, p.117-24, 2003.

CONCI, F.R. Utilização de extrato aquoso e alcoólico de Cyperus rotundus (tiririca) como fitorregulador de enraizamento de Lagerstroemia indica (Extremosa) e da Hydrangea macrophila (Hortênsia). 2004. 44p. Monografia (Graduação em Agronomia) - Universidade Comunitária Regional de Chapecó, Chapecó.

CUDNEY, D. Nutsedge: history, economy, importance and distribution. In: NUTSEDGE MANAGEMENT WORKSHOP, n., 1997, Riverside: University of California, 1997. p. 2-3.

DURIGAN, J.C. et al. Estádios de desenvolvimento e vias de contato e absorção dos herbicidas na inviabilização de tubérculos de Cyperus rotundus. Planta Daninha, v.23, n.4, p.621-6, 2005.

DUTRA, L.F. et al. Época de coleta, ácido indobutírico e triptofano no enraizamento de estacas de pessegueiro. Scientia Agrícola, v.59, n.2, p.327-33, 2002.

FERREIRA, B.G.A. et al. Enraizamento de Sapium glandulatum (Vell.) Pax. pela aplicação de ácido indol butírico e ácido bórico. Leandra, v.16, p.11-16, 2001.

HARTMANN, H.T. et al. Plant Propagation: principles and practices. 7 ed. New York: Englewood Clipps/ Practice Hall, 2002. 880p.

IRITANI, C. et al. Aspectos morfológicos da aplicação de reguladores do crescimento nas estacas de Ilex paraguariensis St. Hilaire. Acta Biológica Paranaense, v.15, p.21-46, 1986.

LORENZI, H.; SOUZA, H.M. Plantas ornamentais no Brasil: Arbustivas, herbáceas e trepadeiras. $3^{a}$ ed. Plantarum, Nova Odessa, Brasil, 2001,1088p.

MEGURO, M. Substâncias reguladoras de crescimento em rizoma de Cyperus rotundus $\mathrm{L}$. Boletim de Botânica, v.33, p.147-71, 1969.

NISSEN, O. MSTAT-C a microcomputer for design, management, and analysis of agronomic research experiments. Version 2.1 East Lansing: Michigan State University, 1993. 300p.

NORBERTO, P.M. et al. Efeito da época de estaquia e do AIB no enraizamento de estacas de figueira (Ficus carica L.). Ciência Agrotécnica, v.25, n.3, p.533-41, 2001.

QUAYYUM, H.A. et al. Growth inhibitory effects of nutgrass (Cyperus rotundus) on rice (Oryza sativa) seedlings. Journal of Chemical Ecology, v.26, n.9, p.2221-31, 2000.

RICCI, M.S.F. et al. Efeitos da solarização do solo na densidade populacional da tiririca e na produtividade de hortaliças sob manejo orgânico. Pesquisa Agropecuária Brasileira, v.35, n.11, p.2175-79, 2000.

ROCHA, S.C. et al. Propagação vegetativa de espirradeira pela técnica da estaquia. Scientia Agraria, v.5, n.1-2, p.73-77, 2004.

SIMÕES, C.M.O. et al. Farmacognosia: da planta ao medicamento. 5. ed. Florianopolis: Ed. da UFSC; Porto Alegre: Ed. da UFRGS, 2003. 1102p.

SOUMAYA, K. et al. Chemical compositon, antibacterical and antimutagenic activities of essential oil from (tunisian) Cyperus rotundus. Journal of Essential Oil Research, v.20, n.3, p.478-84, 2005. 
SOUZA, L.S. et al. Efeito alelopático de plantas daninhas e concentrações de capim-braquiária (Brachiaria decumbens) no desenvolvimento inicial de eucalipto (Eucaliptus grandis). Planta Daninha, v.21, n.3, p.34354, 2003.

TAM, C.U. et al. Optimization and comparison of three methods for extraction of volatile compounds from Cyperus rotundus evaluated by gas chromatographymass spectrometry. Journal of Pharmaceutical and
Biomedical Analysis, v.44, n.2, p.444-47, 2007.

TOFANELLI, M.B.D. et al. Enraizamento de estacas lenhosas e semilenhosas de cultivares de ameixeira com várias concentrações de ácido indolbutírico. Revista Brasileira de Fruticultura, v.24, n.2, p.50913, 2002.

ZUFFELLATO-RIBAS, K.C.; RODRIGUES, J. D. Estaquia: uma abordagem dos principais aspectos fisiológicos. Curitiba: [K. C. Zuffellato-Ribas], 2001, 39p. 